\title{
DAMPAK SEKOLAH LAPANG PENGENDALIAN HAMA TERPADU (SLPHT) TERHADAP TINGKAT PENERAPAN TEKNOLOGI PENGENDALIAN HAMA TERPADU (PHT) \\ PADA USAHA TANI PADI SAWAH (Oryza Sativa L.) \\ (Studi Kasus Pada Kelompok Tani Raksa Bumi III Desa Sindangsari \\ Kecamatan Kawali Kabupaten Ciamis)
}

\author{
Oleh: \\ Asep Dudu Zakil M' ${ }^{1)}$, Yus Rusman' ${ }^{2)}$ Muhamad Nurdin Yusuf ${ }^{3)}$ \\ 1) Mahasiswa Fakultas Pertanian Universitas Galuh \\ 2) Dosen Fakultas Pertanian Universitas Galuh \\ 3) Dosen Fakultas Pertanian Universitas Galuh
}

\begin{abstract}
Abstrak
Penelitian ini dilaksanakan dengan tujuan untuk mengetahui tingkat Dampak Sekolah Lapang Pengendalian Hama Terpadu (SLPHT) Terhadap Tingkat Penerapan Teknologi Pengendalian HamaTerpadu (PHT) Pada Usaha Tani Padi Sawah (Oryza Sativa L.). Penelitian ini dilaksanakan dengan menggunakan metode studi kasus pada Kelompoktani Raksa Bumi III Desa Sindangsari Kecamatan Kawali Kabupaten Ciamis. Sampel penelitian diambil seluruh populasi merupakan pemilihan sampel tidak dilakukan secara subjektif, dalam arti sampel yang terpilih tidak didasarkan semata-mata pada keinginan si peneliti sehingga setiap anggota populasi memiliki kesempatan yang sama (acak) untuk terpilih sebagai sampel. (probability sampling) yaitu sebanyak 50 orang yang tergabung dalam kelompok tani Raksa Bumi III. Data yang dikumpulkan dianalisis secara deskriptif kualitatif. Hasil penelitian menunjukkan bahwa tingkat penerapan teknologi padausahatani padi sawah (Oryza Sativa L.) di Kelompok Raksa Bumi III termasuk dalam kriteria tinggi dengan dampak nyata terhadap tingkat penerapan teknologi PHT pada usaha tani padi sawah (Oryza Sativa L.), karena berdasarkan hasil perhitungan $\chi 2$ hitung yang diperoleh sebesar 48,02 ternyata lebih besar dari nilai kritis $\chi 2$ pada $\alpha=0,05$ (3,841). Tingkat penerapan teknologi PHT yang dicapai sebagian besar responden sebelum mengikuti SLPHT termasuk kedalam kategori rendah, dan setelah mengikuti SLPHT mencapai kategori tinggi terutama pada teknis budidaya tanaman sehat dan pembudidayaan fungsi musuh alami pada tanaman padi sawah (Oryza Sativa L.) Sekolah Lapangan Pengendalian Hama Terpadu (SLPHT), dilaksanakan pada kelompok tani Raksa Bumi III di Desa Sindangsari Kecamatan Kawali Kabupaten Ciamis memberikan dampak positif yang nyata terhadap penerapan tingkat teknologi PHT pada usahatani padi sawah (Oryza Sativa L.)
\end{abstract}

\section{Kata kunci : Tingkat Penerapan Teknologi Pengendalian Hama Terpadu (PHT)}

\section{PENDAHULUAN}

Konsep pertanian berkelanjutan (Sustainable Agriculture) muncul sebagai akibat dari adanya revolusi hijau yang ternyata banyak memberikan banyak dampak negatif dari pada dampak positif. Dalam kebijakan pembangunan pertanian di Indonesia, konsep pertanian berkelanjutan sampai saat ini belum jelas implementasinya. Walaupun asas keberlanjutan pertanian, secara konseptual telah diakomodir dalam Undang-Undang No. 12/1992 tentang Sistem Budidaya Tanaman, "Penerapannya di lapangan masih lemah dan terkesan kontradiktif. Kontradiksi ini terlihat pada tingkatan program pertanian pemerintah." Dillon (2004).

Pertanian di Indonesia belum berfungsi sebagai motor penggerak bagi perekonomian nasional disebabkan banyak faktor, diantaranya adalah pola pembangunan sektor pertanian itu sendiri yang selama ini lebih diarahkan pada tiga tujuan, yaitu: 1) sebagai pemasok makanan (khususnya beras) sehingga kurang usaha-usaha diversifikasi produksi dengan juga memperhatikan kepada pengembangan komoditi nonmakanan, atau yang memiliki nilai komersial tinggi: 2) kebijakan yang ada selama ini lebih mendorong sektor pertanian untuk ekspor langsung, bukan diolah terlebih dahulu di dalam negeri: 3) pemerintah selama ini lebih mementingkan aspek pertumbuhan kesempatan kerja daripada penciptaan nilai tambah dari pembangunan sektor pertanian (Tambunan, 2003). 
Dalam perspektif penyuluhan pertanian, pengembangan SLPHT merupakan proses pelembagaan atau adopsi inovasi sistem usahatani Padi Sawah dalam upaya optimalisasi pemanfaatan lahan sawah irigasi. Perilaku para petani mengembangkan sistem PHT adalah hasil dari proses belajar dan bekerja yang sistematik, berkelanjutan dan terprogram dalam suatu sistem interaksi antara petani sebagai subjek, dengan aparatur penyuluhan pertanian sebagai fasilitator atau pemandunya.

Prinsip PHT dalam SLPHT bukan hanya sebuah pesan ataupun paket kegiatan, tetapi lebih mendalam. PHT adalah sebuah cara untuk mengelola pertumbuhan tanaman sehingga dapat memberikan keuntungan yang maksimal. Terdapat 4 manajemen: yang mendasari PHT yang bersifat luwes, disesuaikan dengan daerah dan lahan setempat. Keempat prinsif tersebut adalah: 1) budidaya tanaman sehat: 2) pelestarian musuh alami: 3) pengamatan berkala: 4) petani ahli PHT (Direktorat Perlindungan Tanaman Pangan, 2004).

Upaya untuk mengatasi serangan OPT di Kabupaten Ciamis telah dilakukan tersebut dengan diperkenalkannya Pengendalian Hama Terpadu (PHT), namun teknologi PHT yang diperkenalkan dan dikembangkan secara luas sejak tahun 1990 ternyata belum sepenuhnya diterapkan para petani yang disebabkan masih adanya berbagai kendala yang dihadapi petani dalam penerapannya (Dinas Pertanian Kabupaten Ciamis, 2006).

Untuk dapat diterapkan oleh para petani, pemerintah terus berupaya untuk mencari cara yang paling efektif, diantaranya dengan menyelenggarakan SLPHT. Kegiatan SLPHT di Kabupaten Ciamis telah dilaksanakan sejak tahun 1990 dan hingga tahun 2006-2013 tercatat sebanyak 768 Kelompok Tani yang telah mengikuti dan tersebar di 36 Kecamatan (Dinas Pertanian Kabupaten Ciamis 2013).

Adanya kegiatan SLPHT, diharapkan para petani anggota kelompok tani Raksa Bumi III diharapkan meningkat pengetahuannya serta mau dan mampu menerapkan teknologi yang telah dikuasainya, sehingga permasalahan serangan OPT di wilayah tersebut dapat diatasi dengan adanya kegiatan SLPHT di Kecamatan Kawali.

Berdasarkan uraian tersebut, maka penulis tertarik untuk melaksanakan penelitian mengenai "Dampak Sekolah Lapangan Pengendalian Hama Terpadu SLPHT Terhadap Tingkat Penerapan Teknologi PHT Pada Usahatani Padi Sawah
(Oryza Sativa L.)" yang merupakan studi kasus pada Kelompok Tani Raksa Bumi III di Desa Sindangsari Kecamatan Kawali Kabupaten Ciamis.

\section{METODOLOGI PENELITIAN Jenis Penelitian}

Jenis penelitian yang akan digunakan dalam penelitian ini adalah studi kasus Wirartha (2005) menyatakan bahwa studi kasus merupakan suatu penelitian yang mendalam mengenai kasus tertentu secara intensif dan mendetil yang hasilnya merupakan gambaran lengkap dan terorganisir mengenainya, dimana objek yang dipelajari sebagai suatu keseluruhan yang terintegrasi dengan menggunakan pendekatan yang bertujuan mempertahankan keutuhan objek penelitian.

Dengan demikian hasilnya hanya berlaku bagi kasus itu sendiri atau tidak dapat digeneralisasikan pada yang di luar kasus tersebut.

\section{Oprasionalisasi Variabel}

Untuk memperjelas dalam analisis data, maka variabel-variabel yang diamati dalam penelitian ini didefinisikan sebagai berikut:

1. SLPHT adalah sekolah lapangan yang fokus muatannya (Contect) mengenai usahatani Padi Sawah.

2. PHT adalah teknologi pengendalian hama terpadu yang menitikberatkan pada pengelolaan ekosistem dengan menerapkan adanya ambang ekonomis, prinsip budaya tanaman sehat serta pelestarian dan pembudidayaan musuh alami.

a. Budidaya tanaman sehat adalah semua cara teknik budidaya tanaman sehingga dapat meningkatkan kesehatan dan produktivitas tanaman, yaitu: 1) Pemilihan bibit yang baik : 2) Penentuan waktu tanam: 3) Pemupukan sesuai dosis: 4) Penyiangan gulma. Penilaiannya dilakukan dengan sistem skoring.

Pelestarian dan pembudidayaan fungsi musuh alami adalah berbagai upaya untuk memfungsikan musuh alami dan mengurangi tindakan-tindakan yang dapat mempengaruhi berkurangnya fungsi musuh alami, yaitu : 1) Teknik bercocok tanam : (sanitasi, penghancuran dan pembersihan tanaman inang, penetapan jarak tanam) : 2) Penggunaan 
Dampak Sekolah Lapang Pengendalian Hama Terpadu (SLPHT) Terhadap Tingkat Penerapan

Teknologi Pengendalian Hama Terpadu (PHT) Pada Usaha Tani Padi Sawah (Oryza Sativa L.)

(Studi Kasus Pada Kelompok Tani Raksa Bumi III Desa Sindangsari

Kecamatan Kawali Kabupaten Ciamis)

ASEP DUDU ZAKIL M, YUS RUSMAN, MUHAMAD NURDIN YUSUF

perangkap : 3) Pengendalian hayati : dan

4) Penggunaan pestisida nabati. Penilaiannya dilakukan dengan sistem skoring.

b. Pengamatan secara teratur merupakan dasar analisis ekosistem untuk mengambil keputusan dan melakukan tindakan yang diperukan, yaitu: 1) tinggi air harus mencapai $0-3 \mathrm{~cm}$ pada umur tanaman 0-3 hari: 2) tinggi air harus mencapai $10 \mathrm{~cm}$ pada umur tanam 4-50 hari: 3) selang waktu pemberian air harus dilakukan selama 10 hari pada tanaman padi: 4) pengambilan sampling pada petakan sawah: 5) melihat populasi hama harus dari sampling. Penilaiannya dilakukan dengan sistem skoring.

c. Petani sebagai ahli PHT memiliki pengetahuan dan keterampilan dalam menganalisis ekosistem serta mampu menetapkan keputusan pengendalian secara tepat sesuai dengan prinsip PHT, yaitu: 1) harus mengetahui apa yang dimaksud ekonomis: 2) harus dapat menghitung nilai ambang ekonomis: 3 ) kerusakan tanaman padi oleh hama serangga: 4) mengetahui hama tanaman padi: 5) penggunaan pestisida yang tepat. Penilaiannya dilakukan dengan sistem skoring.

3. Sebelum SLPHT yaitu sebelum bulan April tahun 2010.

4. Sesudah SLPHT yaitu bulan Agustus tahun 2010 sampai sekarang.

5. Dampak SLPHT adalah perubahan yang terjadi setelah SLPHT selesai dilaksanakan.

6. Budidaya tanaman sehat.

a. Benih yang ditanam harus bersertifikat

b. Benih di uji dengan media garam dan telur

c. Penentuan tanam sesuai dengan anjuran

d. Bibit yang dicabut dari persemaian tanah yang melekat pada tanaman harus di hilangkan

e. Sebelum ditanam sawah harus diberi pupuk organik

7. Pelestarian/ Pembudidayaan Fungsi Musuh Alami

a. Membersihkan lahan dari sisa-sisa tanaman atau bagian tanaman yang tertinggal b. Predator sebagi pemangsa hama tanaman padi

c. Laba-laba sebagi pemangsa hama tanaman padi

d. Pengunaan pestisda secra tepat

e. Penanaman padi dilakukan secara serentak

8. Pengamatan secara teratur/berkala

a. Tinggi air pada umur tanaman 0-3 hari harus $0-3 \mathrm{~cm}$

b. Tinggi air pada umur 4-50 hari harus 10 $\mathrm{cm}$

c. Selang waktu pemberian air dilakukan selama 10 hari

d. Pengambilan sampling pada petakan sawah

e. Melihat populasi hama dari sampling

9. Petani sebagai ahli PHT

a. Harus mengetahui apa yang dimaksud ekonomis

b. Dapat menghitung nilai ambang ekonomis

c. Kerusakan pada tanaman padi oleh hama serangga

d. Mengetahui hama tanaman padi

e. Mengunakan pestisda kimia dengan melihat ambang ekonomis.

\section{Teknik Pengumpulan Data}

Jenis data yang dikumpulkan dalam penelitian ini meliputi data primer dan data sekunder. Data primer diperoleh dari petani yang telah mengikuti kegiatan SLPHT padi sawah yang tergabung dalam Kelompok Tani Raksa Bumi III di Desa Sindangsari dengan melalui wawancara langsung dengan menggunakan kuesioner sebagai alat bantu yang telah disiapkan.

Sebelum kuesioner disebarkan, kuesioner tersebut diuji validitas dan realibilitasnya terlebih dahulu. Validitas adalah tingkat andalan dan kesehatan alat ukur yang digunakan.

\section{Teknik Penarikan Sampel}

Reponden ditentukan secara sensus, yaitu dengan mengambil seluruh petani yang telah mengikuti SLPHT yang tergabung dalam Kelompok Tani Raksa Bumi III di Desa Sindangsari yang berjumlah 50 orang. Sugiyono (2001) menyatakan bahwa populasi adalah wilayah generalisasi yang terdiri atas objek/subjek yang mempunyai kuantitas dan 
karakteristik tertentu yang ditetapkan oleh peneliti untuk dipelajari dan kemudian ditarik kesimpulannya.

\section{Rancangan Analisis Data}

Data primer mengenai karakteristik sosial ekonomi responden dianalisis secara deskriptif. Tingkat penerapan teknologi PHT sebelum dan sesudah petani mengikut SLPHT dibagi ke dalam tiga kategori. Untuk menentukan interval masing,asing kategori dilakukan perhitungan sebagai berikut (Sudjana, 2000).

$$
\begin{aligned}
\text { Panjang Kelas Interval } & =\frac{\text { Rentang }}{\text { Banyak Kelas Interval }} \\
& =\frac{40-20}{3} \\
& =6,667
\end{aligned}
$$

Keterangan:

Rentang = Nilai Maksimal - Nilai Minimal

Banyak Kelas Interval $=$ Jumlah Kategori

Dari rumusan tersebut, maka dapat ditentukan kriteria sebagai berikut:

1. Tingkat Penerapan Teknologi Rendah: $20,000 \leq \mathrm{Q} \leq 26,667$

2. Tingkat Penerapan Teknologi Sedang : $26,667<\mathrm{Q} \leq 33,334$

3. Tingkat Penerapan Teknologi Tinggi : $33,334<\mathrm{Q} \leq 40,000$

Keterangan : $\mathrm{Q}=$ Nilai yang dicapai

Penentuan skor untuk mengukur tingkat penerapan teknologi PHT

Tabel 1 Indikator Tingkat Penerapan Teknologi PHT

\begin{tabular}{|c|l|c|}
\hline No & \multicolumn{1}{|c|}{ Indikator } & $\begin{array}{c}\text { Kisaran } \\
\text { Skor }\end{array}$ \\
\hline 1 & Budidaya tanaman sehat & $10-20$ \\
\hline 2 & $\begin{array}{l}\text { Pelestarian dan } \\
\text { pembudidayaan fungsi } \\
\text { musuh alami }\end{array}$ & $10-20$ \\
\hline \multicolumn{2}{|}{ Jumlah } & $20-40$ \\
\hline
\end{tabular}

Sedangkan untuk mengetahui dampak SLPHT terhadap tingkat penerapan teknologi PHT pada usahatani padi sawah, dianalisis menggunakan statistik non parametrik karena datanya bersifat kualitatif (ordinal) dengan menggunakan uji tanda (Djawanto dan Pangestu, 1981), dengan langkah-langkah pelaksanaan sebagai berikut:

1. Setiap jawaban hasil wawancara dengan responden melalui 20 pertanyaan mengungkapkan indikator terhadap penerapan teknologi PHT pada usahatani Padi Sawah, masing-masing jawaban dari setiap pertanyaan diberi nilai maksimal 2 dan minimal 1. Dengan demikian total nilai maksimal yang mungkin dicapai terhadap penerapan teknologi PHT pada usahatani padi sawah sebelum dan sesudah petani mengikuti kegiatan SLPHT adalah 40.

2. Nilai yang diperoleh responden sebelum SLPHT dimasukan dalam kolom yang dinotasikan $\mathrm{Xi}$, sedangkan nilai sesudah SLPHT dimasukan dalam kolom yang dinotasikan Yi.

3. Nilai setiap responden dalam kolom xi diperbandingkan dengan nilai yang ada dalam kolom Yi, apabila Yi-xi hasilnya positif diberi tanda + , dan apabila Yi-xi hasilnya negatif diberi tanda-.

4. Nilai responden yang bertanda + , - dan yang bertanda 0 dihitung. Setelah itu analisis datanya dilakukan dengan menggunakan rumus sebagai berikut:

$$
\mathrm{x}^{2}=\frac{(|\mathrm{n} 1-\mathrm{n} 2|-1)^{2}}{\mathrm{n} 1+\mathrm{n} 2}
$$

(Sudjana, 2000)

Keterangan :

$\mathrm{n}_{1}=$ Jumlah responden yang nilai Yi-xi nya bertanda Positif (+)

$\mathrm{n}_{2}=$ Jumlah responden yang nilai Yi-xi nya bertanda Negatif (-)

\section{Tempat dan Waktu Penelitian}

Penelitian ini dilaksanakan di Kelompok Tani Raksa Bumi III Desa Sindangsari Kecamatan Kawali Kabupaten Ciamis. Penentuan lokasi ditentukan secara Purposive (sengaja), dengan pertimbangan bahwa Kelompok Tani Raksa Bumi III di Desa Sindangsari merupakan kelompok tani yang paling banyak dibandingkan kelompok tani lain yang telah mengikuti SLPHT padi sawah di Kecamatan Kawali Kabupaten Ciamis.

1. Persiapan penulisan usulan penelitian dilaksanakan bulan Februari 2014.

2. Kegiatan di lapangan untuk mengumpulkan data dilaksanakan pada bulan April sampai dengan Mei 2014.

3. Pengolahan data dan penulisan hasil penelitian akan dilaksanakan pada bulan Juni samapai dengan selesai. 
Dampak Sekolah Lapang Pengendalian Hama Terpadu (SLPHT) Terhadap Tingkat Penerapan Teknologi Pengendalian Hama Terpadu (PHT) Pada Usaha Tani Padi Sawah (Oryza Sativa L.) (Studi Kasus Pada Kelompok Tani Raksa Bumi III Desa Sindangsari

Kecamatan Kawali Kabupaten Ciamis) ASEP DUDU ZAKIL M, YUS RUSMAN, MUHAMAD NURDIN YUSUF

\section{PEMBAHASAN}

\section{Keadaan Umum Daerah Penelitian}

1. Luas Lahan Menurut Ekosistem dan Penggunaannya di Desa Sindangsari Tahun 2013

Luas lahan menurut ekosistem dan penggunaannya di Desa Sindangsari. Mempunyai luas lahan 361.844 hektar, terdiri dari lahan sawah 80 hektar dan lahan kering 201.844 hektar. Luas lahan menurut ekosistem di Desa Sindangsari Tahun 2013 dapat dilihat pada Tabel 2. Tabel ini menunjukkan bahwa ekosistem sawah lahan tadah hujan yang masih dapat ditanami padi di Desa Sindangsari.

Tabel 2 Luas Lahan Menurut Ekosistem dan Penggunaanya di Desa Sindangsari Tahun 2013

\begin{tabular}{|c|l|c|c|}
\hline No & \multicolumn{1}{|c|}{ Ekosistem } & Luas (Ha) & $\%$ \\
\hline 1 & Sawah & - & - \\
\hline & Teknis & - & - \\
\hline & $1 / 2$ teknis & - & - \\
\hline & Pedesaan & 65 & 17,96 \\
\hline & Tanah hujan & 15 & 4,14 \\
\hline & Jumlah Luas Sawah & 80 & 22,11 \\
\hline 2 & $\begin{array}{l}\text { Lahan kering } \\
\text { (darat) }\end{array}$ & - & - \\
\hline & $\begin{array}{l}\text { Pekarangan dan } \\
\text { perumahan }\end{array}$ & 30.9 & 8,54 \\
\hline & Tegalan & 150 & 41,46 \\
\hline & Kebun Campur/HR & - & - \\
\hline & Kolam & 14.74 & 4,08 \\
\hline & Pengangonan & - & - \\
\hline & Hutan Negara & 4.5 & 1,24 \\
\hline & Lain-Lain & 1.704 & 0,47 \\
\hline Jumlah Lahan Kering & 201.844 & - \\
\hline $\begin{array}{l}\text { Luas Sawah dan Lahan } \\
\text { Kering }\end{array}$ & 361.844 & 100 \\
\hline
\end{tabular}

Sumber: Desa Sindangsari, 2013

Tabel 2 menunjukkan bahwa sebagian besar lahan usahatani di Desa Sindangsari digunakan untuk pekarangan atau pemukiman, tegalan atau kebun, kolam, hutan rakyat, sawah dan lain-lain. Luas lahan menurut penggunaannya di Desa Sindangsari menunjukkan bahwa lahan pesawahan paling luas dan paling sedikit lahan kebun campuran yaitu digunakan untuk palawija. Hal tersebut menunjukkan bahwa potensi lahan yang ada sangat mendukung terhadap pengembangan usahatani padi sawah (Oryza Sativa L.) di Desa Sindangsari.
2. Keadaan Penduduk

Jumlah penduduk merupakan sumberdaya yang sangat potensial dalam pembangunan pertanian. Berdasarkan data yang tercatat sampai dengan akhir November 2013, jumlah penduduk Desa Sindangsari sebanyak 3.062 orang, yang terdiri dari 1528 orang laki-laki dan 1.534 orang perempuan.

Dari jumlah penduduk tersebut dapat dikelompokkan berdasarkan kelompok umur yaitu 0-14 tahun, 15-64 tahun dan $\geq 65$ tahun. Secara rinci keadaan penduduk berdasarkan kelompok umur dan jenis kelamin di Desa Sindangsari pada tahun 2013 dapat dilihat pada tabel 3sebagai berikut:

Tabel 3 Jumlah Penduduk Menurut Kelompok Umur di Desa Sindangsari pada Tahun 2013

\begin{tabular}{|c|c|c|c|c|}
\hline \multirow{2}{*}{ No } & \multirow{2}{*}{$\begin{array}{l}\text { Umur } \\
\text { (Th) }\end{array}$} & \multicolumn{3}{|c|}{ Jenis Kelamin } \\
\hline & & Laki-laki & Perempuan & Jumlah \\
\hline 1 & $0-14$ & 365 & 346 & 711 \\
\hline 2 & $15-64$ & 118 & 119 & 237 \\
\hline 3 & $\geq 65$ & 145 & 169 & 314 \\
\hline \multicolumn{2}{|c|}{ Jumlah } & 1528 & 1534 & 3062 \\
\hline
\end{tabular}

Sumber: Desa Sindangsari, 2013

Berdasarkan luas lahan dan jumlah penduduk di Desa Sindangsari maka dapat diketahui:

a. Kepadatan Penduduk per Kilometer Persegi

Hasil perhitungan tersebut menunjukkan bahwa kepadatan penduduk di Desa Sindangsari adalah sebanyak 234 orang per kilometer persegi, hal ini menunjukkan bahwa keadaan penduduk Desa Sindangsari termasuk ke dalam kategori sedang. Hal ini menggambarkan tidak adanya keseimbangan antara jumlah penduduk dengan lahan yang tersedia.

b. Sex Ratio (SR)

Berdasarkan hasil perhitungan diketahui bahwa setiap 100 orang penduduk perempuan di Desa Sindangsari berbanding 99 orang penduduk laki-laki.

c. Forty Percent Test

Berdasarkan hasil perhitungan diketahui bahwa struktur umur penduduk Desa Sindangsari termasuk struktur umur produktif (struktur usia kerja), karena struktur usia mudanya kurang dari 40 persen yaitu 23,22 persen 
d. Dependency Ratio (DR)

Berdasarkan hasil perhitungan tersebut maka dapat diketahui bahwa setiap 100 orang penduduk usia produktif di Desa Sindangsari harus menanggung beban 50 orang penduduk bukan usia produktif.

e. Man Land Ratio (MLR)

Berdasarkan hasil perhitungan tersebut maka di Desa Sindangsari, setiap 1 hektar lahan pertanian digarap atau diusahakan oleh 10 orang penduduk.

3. Keadaan Pendidikan

Berdasarkan data yang tercatat pada akhir tahun 2013, keadaan pendidikan penduduk di Desa Sindangsari dapat dilihat pada Tabel 4 sebagai berikut:

Tabel 4 Keadaan Pendidikan Penduduk di Desa Sindangsari Tahun 2013

\begin{tabular}{|c|c|c|c|}
\hline No & Keadaan Pendidikan & $\begin{array}{l}\text { Jumlah } \\
\text { (orang) }\end{array}$ & $\begin{array}{c}\text { Persen } \\
\text { tase } \\
(\%)\end{array}$ \\
\hline 1 & Belum/Tidak Sekolah & 767 & 25,05 \\
\hline 2 & Tamat SD/Sederajat & 1562 & 51,01 \\
\hline 3 & Tamat SLTP/Sederajat & 498 & 16,27 \\
\hline 4 & Tamat SLTA/Sederajat & 179 & 5,84 \\
\hline 5 & Tamat Akademi & 25 & 0,82 \\
\hline 6 & $\begin{array}{l}\text { Tamat Perguruan } \\
\text { Tinggi }\end{array}$ & 31 & 1,01 \\
\hline & Jumlah & 3.062 & 100,00 \\
\hline
\end{tabular}

Sumber: Desa Sindangsari2013

Berdasarkan pada Tabel 4 maka dapat diketahui bahwa dari 3.062 orang penduduk di Desa Sindangsari telah menempuh pendidikan formal, sebagian besar berpendidikan relatife rendah yaitu tamat SD/Sederajat 1562 orang (51,01 persen).

4. Mata Pencaharian

Secara umum mata pencaharian penduduk Desa Sindangsari cukup beragam dan sebagian besar bekerja di sektor pertanian. Untuk lebih jelasnya keadaaan penduduk di Desa Sindangsari berdasarkan mata pencaharian tahun 2013 dapat dilihat pada Tabel 5sebagai berikut:

Tabel 5 Keadaan Penduduk di Desa Sindangsari Berdasarkan MataPencaharian Tahun 2013

\begin{tabular}{|c|l|c|c|}
\hline No & Mata Pencaharian & $\begin{array}{c}\text { Jumlah } \\
(\text { Orang) }\end{array}$ & $\begin{array}{c}\text { Persentase } \\
(\%)\end{array}$ \\
\hline 1 & Petani & 1.072 & 67,13 \\
\hline 2 & Buruh Tani & 328 & 20,54 \\
\hline 3 & PNS/ ABRI & 70 & 4,38 \\
\hline 4 & Pensiun PNS & 16 & 1,00 \\
\hline 5 & Industri Kecil & 21 & 1,31 \\
\hline
\end{tabular}

\begin{tabular}{|c|c|c|c|}
\hline 6 & Buruh Bangunan & 30 & 1,88 \\
\hline 7 & Pedagang & 60 & 3,76 \\
\hline \multicolumn{2}{|c|}{ Jumlah } & 1.597 & 100,00 \\
\hline
\end{tabular}

Sumber: Desa Sindangsari, 2013

Berdasarkan pada Tabel 5 tersebut maka dapat diketahui bahwa sebagian besar penduduk Desa Sindangsari yaitu 1.072 orang $(67,13$ persen) bekerja pada sektor pertanian baik sebagai petani maupun buruh tani. Keadaan tersebut sangat didukung oleh potensi lahan yang cocok untuk pengembangan sektor pertanian.

5. Kepemilikan Lahan

Penduduk Desa Sindangsari sebagian besar mempunyai lahan kurang dari 1 hektar. Secara lebih jelas keadaan penduduk Desa Sindangsari berdasarkan luas kepemilikan lahan tahun 2013 dapat dilihat pada Tabel 6 sebagai berikut:

\section{Tabel 6 Keadaan Penduduk Desa Sindangsari Berdasarkan Luas Kepemilikan Lahan Tahun 2013}

\begin{tabular}{|c|c|c|c|}
\hline No & $\begin{array}{c}\text { Luas Lahan } \\
(\mathrm{Ha})\end{array}$ & $\begin{array}{l}\text { Jumlah } \\
\text { (orang) }\end{array}$ & $\begin{array}{c}\text { Persentase } \\
(\%)\end{array}$ \\
\hline 1 & $<0,5$ & 982 & 32,99 \\
\hline 2 & $0,5-1$ & 1985 & 66,68 \\
\hline 3 & $>1$ & 10 & 0,33 \\
\hline \multicolumn{2}{|r|}{ Jumlah } & 2.977 & 100,00 \\
\hline
\end{tabular}

Sumber: Desa Sindangsari, 2013

Berdasarkan pada Tabel 6 di atas, bahwa kepemilikan lahan di Desa Sindangsari sebagian besar mempunyai luas lahan < 0,5 hektar yaitu sebanyak 982 orang atau 32,99 persen dan termasuk dalam kategori pemilikan sempit. Kesimpulan tersebut mengacu pada pendapat Hernanto (2002) yang menyatakan bahwa luas kepemilikan lahan $<0,5$ hektar termasuk kategori sempit.

\section{Keadaan Petani}

1. Umur Petani

Petani berusia antara 30-65 tahun.Secara lebih rinci mengenai keadaan petani berdasarkan kelompok umur dapat dilihat pada Tabel 7 sebagai berikut:

\section{Tabel 7 Keadaan Responden Berdasarkan Kelompok Umur}

\begin{tabular}{|c|c|c|c|}
\hline No & $\begin{array}{c}\text { Umur Responden } \\
\text { (Tahun) }\end{array}$ & $\begin{array}{c}\text { Jumlah } \\
\text { (orang) }\end{array}$ & $\begin{array}{c}\text { Persentase } \\
(\%)\end{array}$ \\
\hline 1 & $30-45$ & 34 & 68 \\
\hline 2 & $46-65$ & 16 & 32 \\
\hline & Jumlah & 50 & 100 \\
\hline
\end{tabular}

Sumber: Data Primer diolah, 2013 
Dampak Sekolah Lapang Pengendalian Hama Terpadu (SLPHT) Terhadap Tingkat Penerapan Teknologi Pengendalian Hama Terpadu (PHT) Pada Usaha Tani Padi Sawah (Oryza Sativa L.) (Studi Kasus Pada Kelompok Tani Raksa Bumi III Desa Sindangsari

Kecamatan Kawali Kabupaten Ciamis)

ASEP DUDU ZAKIL M, YUS RUSMAN, MUHAMAD NURDIN YUSUF

Tabel 7 menunjukkan bahwa pada kelompok umur terbagi dalam dua kategori. Total jumlah responden yang mengikuti kegiatan SLPHT padi sawah (Oryza Sativa L.) yaitu didominasi oleh kelompok umur 30 - 45 tahun, sebanyak $68 \%$ (34 orang). Sebagian dari responden yang tergolong kelompok umur 46 - 65 tahun, sebanyak 32\% (16 orang). Hal tersebut pada kelompok umur termasuk kedalam usia produktif karena umur berkisar $30-65$ tahun, hal tersebut dimaksudkan untuk mempermudah dalam proses pengamatan karena pada SLPHT padi sawah (Oryza Sativa L.) memerlukan tenaga ekstra diantaranya untuk pengamatan.

\section{Keadaan Pendidikan Responden}

Tingkat pendidikan formal yang pernah ditempuh sebagian besar petani hanya sampai tingkat Sekolah Dasar.Keadaan pendidikan responden dapat dilihat pada Tabel 8 sebagai berikut:

Tabel 8 Keadaan Pendidikan Responden

\begin{tabular}{|c|l|c|c|}
\hline No & $\begin{array}{c}\text { Tingkat } \\
\text { Pendidikan }\end{array}$ & $\begin{array}{c}\text { Jumlah } \\
\text { (orang) }\end{array}$ & $\begin{array}{c}\text { Persentase } \\
(\%)\end{array}$ \\
\hline 1 & SD & 21 & 42 \\
\hline 2 & SLTP & 13 & 26 \\
\hline 3 & SMA & 16 & 32 \\
\hline \multicolumn{2}{|c|}{ Jumlah } & 25 & 100 \\
\hline
\end{tabular}

Sumber: Data Primer Diolah, 2014

Tabel 8 menunjukkan bahwa pada keadaan pendidikan terbagi dalam tiga kategori (SD, SLTP, SMA). Total jumlah responden yaitu didominasi oleh tingkat SD 21 orang, sebanyak 68\% (42 orang), tingkat SLTP 13 orang, sebanyak 26\% (13 orang) dan tingkat SMA 16 orang, sebanyak $32 \%$ (16 orang).Rendahnya tingkat pendidikan responden disebabkan oleh keterbatasan cara berfikir dari para orang tua mereka ditambah biaya yang tinggi dan pada umumnya tidak terjangkau oleh orang tua responden pada saat itu.

3. Jumlah Tanggungan Keluarga Responden

Tanggungan keluarga petani pada penelitian ini terdiri dari istri, anak, dan anggota keluarga lainnya yang menjadi tanggungan kepala keluarga. Jumlah tanggungan keluarga petani di Desa Sindangsari dapat dilihat pada Tabel 9.
Tabel 9 Jumlah Tanggugan Keluarga Responden

\begin{tabular}{|c|c|c|c|}
\hline No & $\begin{array}{c}\text { Tanggungan } \\
\text { Keluarga }\end{array}$ & $\begin{array}{c}\text { Jumlah } \\
\text { (orang) }\end{array}$ & $\begin{array}{c}\text { Persentase } \\
(\%)\end{array}$ \\
\hline 1 & $<3$ & 30 & 60 \\
\hline 2 & 3 & 20 & 40 \\
\hline \multicolumn{2}{|c|}{ Jumlah } & 50 & 100 \\
\hline
\end{tabular}

Sumber: Data Primer Diolah, 2014

Tabel 9 menunjukkan bahwa sebagian besar petani yaitu sebanyak 30 orang atau $60 \%$ mempunyai tanggungan keluarga kurang dari 3 orang.

4. Luas Kepemilikan Lahan Usaha Tani Responden

Tabel 10 Luas Kepemilikan Lahan Usaha Tani Tahun 2013

\begin{tabular}{|c|c|c|c|}
\hline No & $\begin{array}{c}\text { Luas } \\
\text { Lahan (Ha) }\end{array}$ & $\begin{array}{c}\text { Jumlah Lahan } \\
\text { Responden } \\
\text { (orang) }\end{array}$ & $\begin{array}{c}\text { Persentase } \\
(\%)\end{array}$ \\
\hline 1 & $<0,5$ & 36 & 72 \\
\hline 2 & $0,5-1$ & 11 & 22 \\
\hline 3 & $>1$ & 3 & 06 \\
\hline \multicolumn{2}{r|}{ Jumlah } & 50 & 100 \\
\hline
\end{tabular}

Sumber: Data Primer Diolah, 2014

Tabel 10 di atas, bahwa kepemilikan lahan usaha tani sebagian besar mempunyai luas lahan $<0,5$ hektar yaitu sebanyak 36 responden atau 72 persen dan termasuk dalam kategori pemilikan sempit. Luas kepemilikan lahan usaha tani petani berkisar antara 0,07 sampai 1,5 hektar. Lebih jelas dapat dilihat pada lampiran 6. Hernanto (2002) yang menyatakan bahwa kepemilikan lahan kurang dari 0,5 hektar termasuk kategori sempit, 0,5 sampai 1 hektar termasuk kategori sedang, dan apabila lebih dari 1 hektar termasuk kategori yang luas.

5. Pengalaman Berusaha Tani Responden

Pengalaman berusahatani responden berkisar antara 7 sampai 30 tahun yang secara lebih jelas dapat dilihat pada Tabel 11 sebagai berikut:

Tabel 11 Pengalaman Berusaha Tani Responden

\begin{tabular}{|c|c|c|c|}
\hline No & $\begin{array}{c}\text { Pengalaman } \\
\text { Usahatani (Tahun) }\end{array}$ & $\begin{array}{c}\text { Jumlah } \\
\text { (Orang) }\end{array}$ & $\begin{array}{c}\text { Persentase } \\
(\%)\end{array}$ \\
\hline 1 & $7-11$ & 20 & 40 \\
\hline 2 & $12-15$ & 15 & 30 \\
\hline 3 & $16-23$ & 15 & 30 \\
\hline \multicolumn{2}{|c|}{ Jumlah } & 50 & 100 \\
\hline
\end{tabular}

Sumber: Data Primer, 2014 
Tabel 11 memperlihatkan bahwa sebagian besar petani memiliki pengalaman berusahatani 16-23 tahun yaitu 15 orang (30 persen).

Tingkat Penerapan Teknologi PHT Sebelum dan Sesudah Petani Mengikuti SLPHT

1. Tingkat Penerapan Teknologi PHT Sebelum Petani Mengikuti SLPHT

Tingkat penerapan teknologi PHT padi sawah (Oryza Sativa L.) sebelum petani mengikuti SLPHT sebagian besar masih rendah. Sebelum mengikuti SLPHT petani melaksanakan kegiatan budidaya secara tradisional, belum mengenal teknologi budidaya yang dianjurkan oleh pemerintah. Tingkat penerapan teknologi PHT yang meliputi komponen teknologi budidaya tanaman sehat dan pelestarian atau pembudidayaan fungsi musuh alami pada usaha tani padi sawah (Oryza Sativa L.) di Kelompok Tani Raksa Bumi III sebelum petani mengikuti SLPHT dapat dilihat pada Tabel 12 sebagai berikut:

Tabel 12 Tingkat Penerapan Teknologi PHT Sebelum Petani Mengikuti SLPHT

\begin{tabular}{|c|c|c|c|c|}
\hline No & $\begin{array}{c}\text { Tingkat } \\
\text { Penerapan } \\
\text { Teknologi } \\
\text { PHT }\end{array}$ & Nilai & $\begin{array}{c}\text { Jumlah } \\
\text { (orang) }\end{array}$ & $\begin{array}{c}\text { Persen } \\
\text { tase } \\
(\%)\end{array}$ \\
\hline 1 & Rendah & $\begin{array}{c}20,000 \\
\leq \mathrm{Q} \leq \\
26,667\end{array}$ & 29 & 58 \\
\hline 3 & Sedang & $\begin{array}{c}26,667 \\
\leq \mathrm{Q} \leq \\
33,334\end{array}$ & 21 & 42 \\
\hline \multirow{5}{|c|}{ Jumlah } & $\begin{array}{c}33,334 \\
\leq \mathrm{Q} \leq \\
40,000\end{array}$ & 0 & 0 \\
\hline
\end{tabular}

Sumber: Data Primer Diolah, 2014

Tabel 12menunjukkan bahwa sebagian besar responden sebelum mengikuti kegiatan SLPHT yaitu 29 orang atau 58 persen tingkat penerapan teknologi PHT yang dicapai termasuk kategori rendah, sisanya sebanyak 21 orang atau 42 persen termasuk kategori sedang. Hal tersebut mengindikasikan kurangnya pengetahuan responden terhadap budidaya tanaman sehat dan pelestarian atau pembudidayaan fungsi musuh alami yang dapat meningkatkan pendapatan dari usaha tani yang dijalaninya, sehingga perlu ditingkatkan dengan pemberian pendidikan, salah satunya melalui kegiatan SLPHT agar petani lebih memahami dan dapat menigkatkan penerapannya. Banyak hal yang menyebabkan rendahnya tingkat penerapan PHT termasuk kategori rendah diantaranya tingkat pendidikan yang rendah seperti telah dibahas pada bab sebelumnya mengenai keadaan pendidikan responden bahwa sebagian besar responden berpendidikan SD, kurang aktifnya petani kelompok tani dan aparatur pemerintahan desa terhadap perkembangan teknologi pertanian.

2. Tingkat Penerapan Teknologi PHT Sesudah Petani Mengikuti Kegiatan SLPHT

Tingkat penerapan teknologi PHT pada usaha tani padi sawah (Oryza Sativa L.) di Kelompok Tani Raksa Bumi III sesudah mengikuti kegiatan SLPHT mayoritas menjadi lebih baik. Petani menjadi tahu tentang bagaimana cara budidaya padi sawah (Oryza Sativa L.) yang baik, sehat dan menguntungkan.

Setelah mengikuti SLPHT cara budidaya yang dilakukan oleh petani relatip sudah sesuai dengan anjuran sehingga produktivitas padi meningkat.

Tingkat penerapan teknologi PHT pada usaha tani padi sawah (Oryza Sativa L.) di Kelompok Tani Raksa Bumi III sesudah mengikuti SLPHT dapatdilihat pada Tabel 13.

Tabel 13 Tingkat Penerapan Teknologi PHT Sesudah Petani Mengikuti SLPHT

\begin{tabular}{|c|c|c|c|c|}
\hline No & $\begin{array}{c}\text { Tingkat } \\
\text { Penerapan } \\
\text { Teknoligi } \\
\text { PHT }\end{array}$ & Nilai & $\begin{array}{l}\text { Jumlah } \\
\text { (orang) }\end{array}$ & $\begin{array}{c}\text { Persen } \\
\text { tase }(\%)\end{array}$ \\
\hline 1 & Rendah & $\begin{array}{c}20,000 \\
\leq \mathrm{Q} \leq \\
26,667\end{array}$ & 1 & 2 \\
\hline 2 & Sedang & $\begin{array}{c}26,667 \\
\leq \mathrm{Q} \leq \\
33,334\end{array}$ & 8 & 16 \\
\hline 3 & Tinggi & $\begin{array}{c}33,334 \\
\leq \mathrm{Q} \leq \\
40,000\end{array}$ & 41 & 82 \\
\hline & Jumlah & & 50 & 100 \\
\hline
\end{tabular}

Sumber: Data Primer Diolah, 2014

Tabel 13menunjukkan bahwa sebagian besar responden sesudah mengikuti kegiatan SLPHT yaitu 41 orang atau 82 persen tingkat penerapan teknologi PHT yang dicapai termasuk kategori tinggi. Hal ini mengidikasikan bahwa bentuk pelatihan, sekolah lapangan, cara belajar dengan menggunakan POD (mengalami/melakukan, mengungkapkan, menganalisa, menyimpulkan, menerapkan) dapat meningkatkan pengetahuan maupun keterampilan petani dalam 
Dampak Sekolah Lapang Pengendalian Hama Terpadu (SLPHT) Terhadap Tingkat Penerapan Teknologi Pengendalian Hama Terpadu (PHT) Pada Usaha Tani Padi Sawah (Oryza Sativa L.) (Studi Kasus Pada Kelompok Tani Raksa Bumi III Desa Sindangsari

Kecamatan Kawali Kabupaten Ciamis) ASEP DUDU ZAKIL M, YUS RUSMAN, MUHAMAD NURDIN YUSUF

melaksanakanteknologi baru sehingga dapat diterapkan dalam usaha taninya dan meningkatkan produksi, pendapatan, serta kesejahteraan.

\section{Dampak SLPHT Terhadap Tingkat Penerapan Teknologi PHT Pada Usaha Tani Padi Sawah (Oryza Sativa L.)}

Tingkat penerapan teknologi PHT pada usaha tani padi sawah (Oryza Sativa L.) menunjukkan perubahan ke arah positif (perhitungan dapat dilihat pada lampiran 9). Hal tersebut menunjukkan bahwa kegiatan SLPHT memberikan dampak positif terhadap penerapan teknologi PHT pada usahatani padi sawah (Oryza Sativa L.). Setelah dilakukan pengujian dengan menggunakan uji tanda diketahui bahwa kegiatan SLPHT mempunyai dampak nyata terhadap tingkat penerapan teknologi PHT pada usaha tani padi sawah (Oryza Sativa L.), karena berdasarkan hasil perhitungan $\chi^{2}$ hitung yang diperoleh sebesar 48,02 ternyata lebih besar dari nilai kritis $\chi^{2}$ pada $\alpha=0,05(3,841)$. Untuk lebih jelasnya hasil perhitungan uji tanda dapat dilihat pada Lampiran 10.

Kegiatan SLPHT yang telah dilaksanakan memberikan wawasan kepada petani mengenai pentingnya teknologi PHT dalam upaya meningkatkan pendapatan petani, sehingga setelah mengikuti SLPHT, petani dapat mengerti dan menerapkannya.

\section{KESIMPULAN DAN SARAN \\ Kesimpulan}

Berdasarkan pembahasan maka dapat diambil kesimpulan sebagai berikut.

1. Tingkat penerapan teknologi PHT yang dicapai sebagian besar responden sebelum mengikuti SLPHT termasuk kedalam kategori rendah, dan setelah mengikuti SLPHT mencapai kategori tinggi terutama pada teknis budidaya tanaman sehat dan pembudidayaan fungsi musuh alami pada tanaman padi sawah (Oryza Sativa L.).

2. Sekolah Lapangan Pengendalian Hama Terpadu (SLPHT), dilaksanakan pada kelompok tani Raksa Bumi III di Desa Sindangsari Kecamatan Kawali Kabupaten Ciamis memberikan dampak positif yang nyata terhadap penerapan tingkat teknologi PHT pada usahatani padi sawah (Oryza Sativa L.)

\section{Saran}

Berdasarkan kesimpulan tersebut maka saran yang diberikan adalah:

1. Kelembagaan kelompok tani yang sudah ada harus dibina terus dan dikembangkan untuk anggota dalam usaha bersama kelompok, agar kesejahteraan kelompok biasa meningkat.

2. Monitoring dan pembinaan berkelanjutan setelah pelaksanaan SLPHT yang dilaksanakan pada kelompok tani Raksa Bumi III di Desa Sindangsari, perlu terus dilakukan oleh para penyuluh dan POPT agar para petani terus menerapkan teknologi yang didapatnya pada saat mengikuti SLPHT.

\section{DAFTAR PUSTAKA}

Arsyad, Lincolin. 2004. Ekonomi Pembangunan. STIE YKPN. Yogyakarta.

BP3K Kecamatan Kawali. 2013. Data Kegiatan Sekolah Lapangan Pengendalian Hama Terpadu (SLPHT) di Kecamatan Kawali Tahun 2013. Ciamis.

2013. Kelompok Tani Peserta Sekolah Lapangan Pengendalian Hama Terpadu dan Tahun Penyelenggaraan di Desa Sindangsari. Ciamis.

Alisyahbana, Danny. 2008. Hubungan FaktorFaktor Karakteristik Petani Peserta (SLPHT) Terhadap Tingkat Penerimaan Informasi Pengendalian Hama Terpadu (PHT) Tanaman Padi. Terdapat pada http://digilib.unej.ac.id/print.php?id=gdlhubgdl-grey-2008-mdennyalis-

$1227 \&$ PHPSESSID $=95 \mathrm{a} 82 \mathrm{c} 172$

bae52782a942520ff62893a. Diakses 27

Maret 2014.

Cahyono, (2008). Evaluasi Program Sekolah Lapang Pengendalian Hama Terpadu SLPHT Tanaman Padi (Oryza Sativa Sp) di Kelompok Tani Sari Asih Desa Mayang Kecamatan Gatak Kabupaten Sukoharjo.

Departemen Pertanian. 2009. Dasar Dasar Penyuluhan Pertanian.

http://www.pustaka.deptan.go.id.

Departemen Pertanian. Jakarta. 1997. Panduan Sekolah Lapangan . Departemen Pertanian.Jakarta.

Dinas Pertanian Kabupaten Ciamis. 2004. Laporan Tahunan. Dinas Pertanian Kabupaten Ciamis . Ciamis. 
2013. Kegiatan Sekolah Lapangan Pengendalian Hama Terpadu (SLPHT) di Kabupaten Ciamis Tahun 2013. Ciamis.

Direktoran Perlindungan Tanaman Pangan. 2004. Modul Penyuluhan SLPHT. Departemen Pertanian . Jakarta.

Direktorat Perlindungan Tanaman Direktorat Jenderal Bina Produksi Tanaman Pangan. 2002. Pedoman Rekomendasi Pengendalian Hama Terpadu Pada Tanaman Padi. Departemen Pertanian. Jakarta.

Dillon, H.S. 2004. "Pertanian Membangun Bangsa". Dalam Masroh, H. Antoji, dkk (penyusun). Pertanian Mandiri : Pandangan Strategis Para Pakar untuk Kemajuan Pertanian Indonesia Jakarta: Penebar Swadaya. Hlm. 23-36.

Djarwanto dan Pangestu S.1981. Statistik Non Parametrik .Fakultas Ekonomi Universitas Gadjah Mada. Yogyakarta.

Djojosumarto, Panut. 2000. Teknik Aplikasi Pestisida Pertanian. Kanisius, Yogyakarta. Hal 46.

Hutagalung (2011).Evaluasi Terhadap Petani Peserta Program Penyuluhan Pertanian SLPHT di Desa Hutagaol, Kecamatan Balige, Kabupaten Toba Samosir.

I Made Wirartha, 2005. Metodologi Penelitian Sosial Ekonomi. Yogyakarata.

Kartasapoetra, A. G. dan M. M. Sutedjo. 2007.Teknologi Konservasi Tanahdan Air. Rineka Cipta, Jakarta.

Loekman, S.1987. Memantapkan Penyuluhan Pertanian di Indonesia.Proseding Kongres Penyuluhan Pertanian. Perhimpunan Penyuluhan Pertanian Indonesia. Subang.

Mubyarto.1982. Pengantar Ekonomi Pertanian .LP3ES. Jakarta.

Mudrikah (2013). Dampak Sekolah Lapangan Pengendalian Hama Terpadu SLPHT Padi Sawah Terhadap Tingkat Penerapan Teknologi PHT Pada Usaha Tani Manggis (Gracinia Mangostana, L.) di Kelompok Tani Mulyajaya di Desa Parakanmanggu Kecamatan Parigi Kabupaten Ciamis.

Natawigena, H. 2006. Pengendalian Hama Terpadu (Integrated Pest Control). Armico, Bandung. Hal. 40-41.

Nugroho, W. 2004. Sekolah Lapangan Untuk Pemberdayaan Petani Kecil. FIELD Indonesia. Jakarta.

Oka, N. I. 2003. Pengendalian Hama Terpadu dan Implementasinya di Indonesia, UGM Press, Yogyakarta.
Pracaya. 2006. Bertanam Sayuran Organik di Kebun, Pot dan Polibag. Penebar Swadaya. Jakarta.

Paramitakirti (2006). SLPHT Terhadap Perilaku Petani Dan Produktivitas Tanaman Jeruk Siam di Desa Karangsono Kecamatan Bangsalsari dan Desa Sukoreno Kecamatan Umbulsari.

Samsudin. 2008. Virus Patogen Serangga:BioInsektisida Ramah Lingkungan. Diunduh dari http://LembagaPertanian Sehat/Develop Useful Innovation For Famers Rubrik (20 desember 2010).

Sudjana. 2000. Statistika Untuk Ekonomi dan Niaga. Tarsito. Bandung.

Sugiyono (2001). Metode Penelitian Bisnis, Bandung, CV. Alfabeta (2013). Statistik untuk penelitian, CV. Alfabeta, Bandung (2013). Metode Penelitian Bisnis, Bandung, CV. Alfabeta

Tambunan, Tulus. 2003. Perkembangan Sektor Pertanian di Indonesia : Beberapa Isu Penting. Jakarta: Ghalia Indonesia.

Tarigan, R. 2005. Ekonomi+ Regional. PT Bumi Aksara. Jakarta

Untung K. 2003. Konsep Pengendalian Hama Terpadu, Andi Offset. Yogyakarta. 2009. Konsep Pngendalian Hama Terpadu. Andi Offset Yogyakarta. 